\title{
Docetaxel plus cetuximab as second-line treatment for docetaxel-refractory oesophagogastric cancer: the AGITG ATTAX2 trial
}

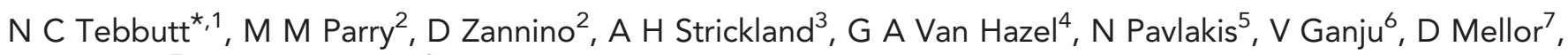
A Dobrovic ${ }^{7}$, and V J Gebski ${ }^{2}$ on behalf of the Australasian Gastro-Intestinal Trials Group (AGITG)

${ }^{1}$ Department of Medical Oncology, Austin Health, PO Box 5555, Studley Road, Heidelberg, Melbourne, Victoria 3084, Australia; ${ }^{2}$ National Health and Medical Research Council Clinical Trials Centre, University of Sydney, Locked Bag 77, Camperdown, Sydney, New South Wales 1450, Australia; ${ }^{3}$ Monash Medical Centre, 246 Clayton Road, Clayton, Melbourne, Victoria 3168, Australia; ${ }^{4}$ Sir Charles Gairdner Hospital, Hospital Avenue, Nedlands, Perth, Western Australia 6009, Australia; ${ }^{5}$ Royal North Shore Hospital, Pacific Highway, St Leonards, Sydney, New South Wales 2064, Australia; ${ }^{6}$ Frankston Hospital, PO Box 52, Frankston, Melbourne, Victoria 3199, Australia and ${ }^{7}$ Peter MacCallum Cancer Centre, St Andrews Place, East Melbourne, Melbourne, Victoria 3002, Australia

Background: Cetuximab can reverse chemotherapy resistance in colorectal cancer. This study evaluated the efficacy and safety of the combination of docetaxel and cetuximab as a second-line treatment in docetaxel-refractory oesophagogastric cancer.

Methods: Patients received docetaxel $30 \mathrm{mg} \mathrm{m}^{-2}$ on days 1 and 8 , every 3 weeks and cetuximab $400 \mathrm{mg} \mathrm{m}^{-2}$ on day 1 , then $250 \mathrm{mg} \mathrm{m}^{-2}$ weekly. Biomarker mutation analysis was performed.

Results: A total of 38 patients were enrolled. Response rates were PR 6\% (95\% Cl 2-19\%), s.d. 43\% (95\% Cl 28-59\%). Main grade $3 /$ 4 toxicities were febrile neutropenia, anorexia, nausea, diarrhoea, stomatitis, and acneiform rash. Median progression-free and overall survival were 2.1 and 5.4 months, respectively. A landmark analysis showed a trend to improved survival times with increased grade of acneiform rash. No KRAS, BRAF or PIK3CA mutations were observed.

Conclusion: Cetuximab and docetaxel achieve modest responses rates, but maintain comparable survival times to other salvage regimens with low rates of toxicity.

We have shown that weekly docetaxel-based regimens have encouraging activity in oesophagogastric cancer, and less haematologic toxicity than 3-weekly regimens (Tebbutt et al, 2010). Synergy between taxanes and HER-targeted therapies has been observed in tumour types such as breast cancer (Slamon et al, 2001), suggesting that the combination of docetaxel and cetuximab may be of interest. This combination has been administered safely in non-small cell lung cancer patients (Kim et al, 2009). Also, cetuximab has been shown to reverse chemotherapy resistance in irinotecan-refractory colorectal cancer (Cunningham et al, 2004). This ability to potentiate previously ineffective treatments may offer an important salvage treatment for patients with an otherwise very poor prognosis.

Given this background, this study tested the combination of weekly docetaxel with cetuximab in docetaxel-refractory patients with oesophagogastric cancer. 


\section{MATERIALS AND METHODS}

Eligibility. The AGITG ATTAX2 study was approved by the Research Ethics Committee of each participating institution. All patients provided written informed consent.

The ATTAX2 study was available for patients who had participated in the ATTAX study, receiving prior weekly docetaxel (Tebbutt et al, 2010) and who progressed either during or within 6 months of docetaxel-based chemotherapy according to the Response Evaluation Criteria in Solid Tumours (RECIST) version 1.0.

Recruitment was initially restricted to patients whose tumours had detectable EGFR as assessed by immunohistochemistry and was amended in December 2005 to include any EGFR status.

Study design and treatment. The ATTAX2 study was a nonrandomised, phase II, open-label, multicentre study of a weekly docetaxel schedule with cetuximab.

Patients received: docetaxel (Taxotere; Sanofi-Aventis, Paris, France) $30 \mathrm{mg} \mathrm{m}^{-2}$ (or at the last dose given on the ATTAX study, if the dose had been reduced due to toxicity) on days 1 and 8 every 3 weeks; and cetuximab (Erbitux; Merck KGaA, Darmstadt, Germany) $400 \mathrm{mg} \mathrm{m}^{-2}$ on day 1 , then $250 \mathrm{mg} \mathrm{m}^{-2}$ weekly.

Treatment continued in the absence of disease progression or request by the patient or physician.

Evaluation and outcomes. Patients were assessed clinically at baseline, before every treatment cycle, and radiographically every 6 weeks.

Quality of life was assessed with the European Organisation for Research and Treatment of Cancer Quality of Life Questionnaire C30, Version 3.0 (1 February 2003), together with the oesophagealspecific module (OES 18) or the gastric module (STO 22), depending on the site of disease.

Statistical analysis. The primary clinical endpoint of the study was response rate, as assessed by RECIST version 1.0. Secondary endpoints were overall survival (OS), progression-free survival (PFS), treatment-related toxicity, disease-associated symptoms, and quality of life.

The study used a Simon's two-stage design. The first stage required two or more confirmed responses in the first 17 patients. The second stage involved complete accrual to 35 patients.

Treatment was expected to achieve a response rate of $20 \%$. The lowest limit of therapeutic effect considered to be of interest was a response rate of $6 \%$. Based on these limits, and $80 \%$ power and a $95 \%$ confidence level, five or more responses in the total cohort were required to determine that a regimen was active.

KRAS, BRAF and PIK3CA analysis. Mutational status of KRAS, $B R A F$ and PIK3CA was determined using high-resolution melt analysis as described in the Supplementary Information (Krypuy et al, 2006; Do and Dobrovic, 2012). Correlation of results to response rate, $\mathrm{PFS}$, and OS was performed using a Cox regression model.

\section{RESULTS}

Patient characteristics. Between April 2005 and February 2007, 38 patients were registered from nine institutions in Australia. One patient was ineligible because they had no measurable disease, and two patients had only 8 days of treatment and no subsequent valid RECIST tumour assessments. Baseline characteristics are described in Supplementary Table 1.

Treatment. The median number of cycles delivered per patient was 2, with a range of 1-15. Dose intensities compared

\begin{tabular}{|c|c|c|}
\hline $\boldsymbol{n}=35$ evaluable points & Number & $\begin{array}{c}\% \text { (95 \% confidence } \\
\text { interval) }\end{array}$ \\
\hline $\begin{array}{l}\text { Confirmed complete } \\
\text { response }\end{array}$ & 0 & $0(0-10)$ \\
\hline Confirmed partial response $^{a}$ & 2 & $6(2-19)$ \\
\hline Stable disease ${ }^{\mathbf{b}}$ & 15 & $43(28-59)$ \\
\hline Progressive disease & 18 & $51(36-67)$ \\
\hline
\end{tabular}

with the starting dosages were: docetaxel, 99\%; and cetuximab, $99 \%$. Treatment delays of more than 1 week occurred for five patients (13\%).

Efficacy. The interim response analysis met the criterion for the study to continue. Of the 38 final patients recruited, 35 patients were assessable for response, none had a complete response, 2 had a partial response, and 15 had stable disease (Table 1). Tumour progression had occurred within 9 and 13 days of docetaxel in the patients with response, indicating that both cases were refractory to docetaxel. A waterfall plot of unconfirmed responses showed additional evidence of minor degrees of tumour regression (Figure 1).

At the median follow-up time of 18.9 months, all patients had died. Median PFS was 2.1 months (Figure 2A), and median OS was 5.4 months (Figure $2 \mathrm{~B}$ ).

Toxicity. Toxicity is summarised in Supplementary Table 2. One patient had grade 4 febrile neutropenia. The most significant common adverse events were grade 3 or 4 fatigue, grade 3 anorexia, grade 3 diarrhoea, grade 3 nausea, grade 3 acneiform rash, and grade 3 stomatitis.

A landmark analysis showed a trend to improved survival times with increased grade of acneiform rash (grade $0 v s$ grade 1: HR 0.73 (95\% CI 0.32-1.66), $P=0.45$; grade 0 vs grade $2 / 3$ : HR $0.58(95 \%$ CI $0.22-1.50), P=0.26$ ) (Figure 3 ).

Disease-associated symptoms and quality of life. Improvement in a specific disease-associated symptom or aspect of quality of life was defined as an increase of 10 points or more for that questionnaire item for more than 3 weeks. Improvement in global health and quality of life was seen in $27 \%$ of patients, nausea and vomiting in $18 \%$, fatigue in $33 \%$, and pain in $40 \%$, respectively. The most striking improvement was in dysphagia in patients with oesophageal disease, among whom 50\% improved, compared with $27 \%$ of patients with gastric disease.

KRAS, BRAF, and PIK3CA analysis. Of the 38 patients that participated in the study, 37 consented to tissue banking. Of 31 samples received, 3 further samples were unsuitable for testing. Of the 28 samples from which DNA was extracted, genotyping was not possible for almost half of these samples due to sample size, tumour purity, DNA quality and so on. Of the genotyped samples, $100 \%$ were wild type for KRAS exon 2 (18 out of 18 patients), $B R A F$ exon 15 (17 out of 17 patients), and PI3KCA exon 20 (18 out of 18 patients). Of the ATTAX2 responders, one was wild type for KRAS exon 2, BRAF exon 15, and PI3KCA exon 20, and it was not possible to genotype the other responder for the reasons already stated. Therefore, no correlation between ATTAX2 response and $K R A S, B R A F$, or PI3KCA status could be determined. 


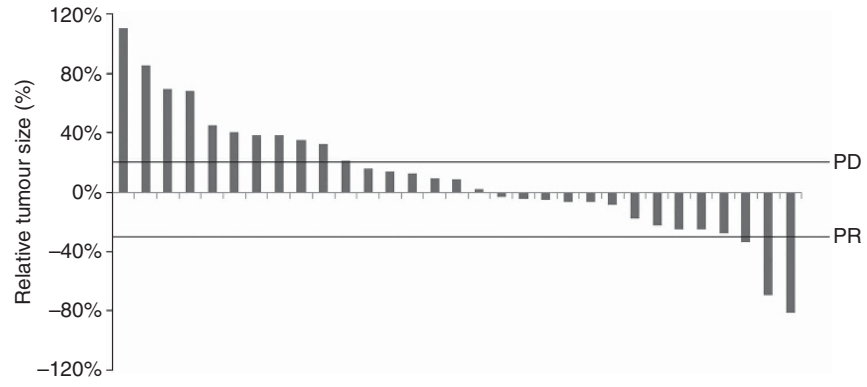

Figure 1. Waterfall plot showing tumour size at best unconfirmed response relative to tumour size at baseline $(n=31)$.
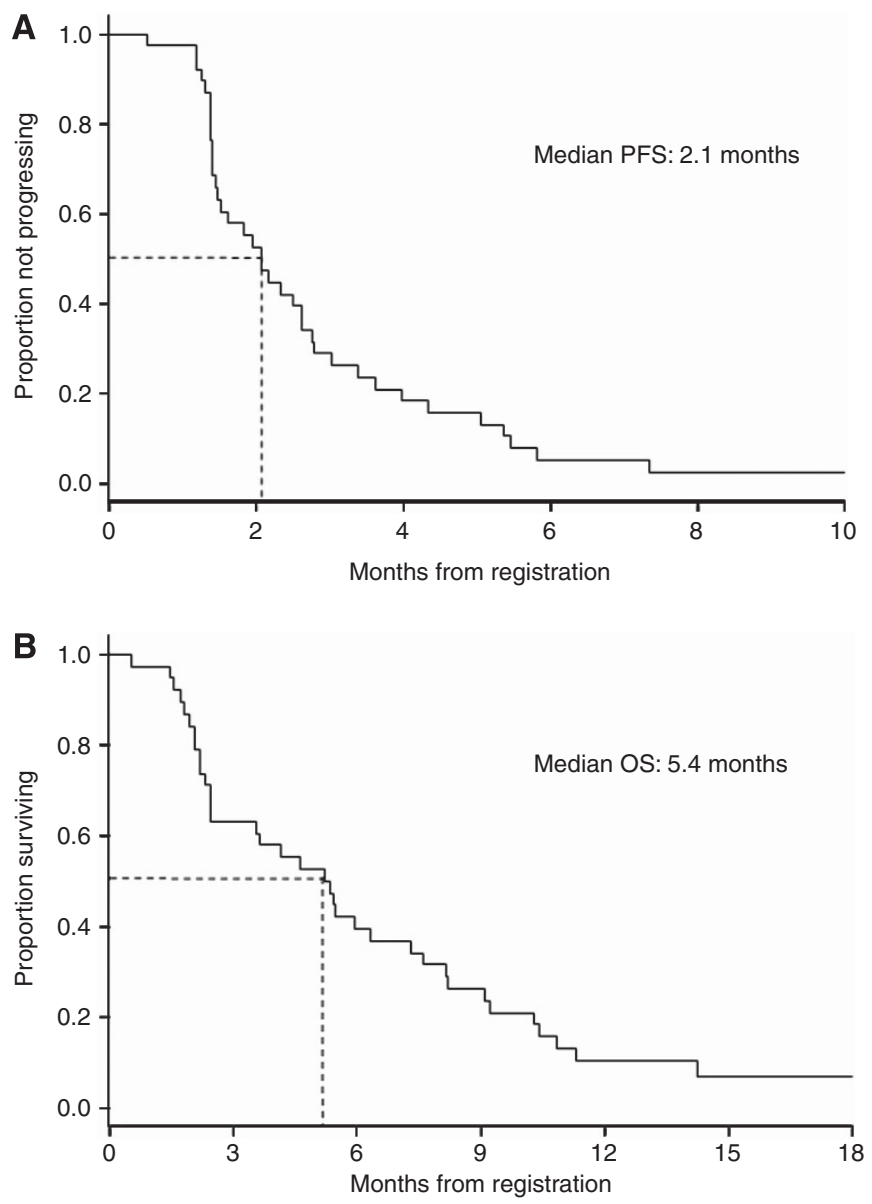

Figure 2. Kaplan-Meier curves of progression-free survival (A) and overall survival (B) for advanced oesophagogastric cancer patients treated with weekly docetaxel plus cetuximab $(n=38)$.

\section{DISCUSSION}

There is no consensus therapy for second-line treatment of advanced oesophagogastric cancer. Randomised studies support use of an irinotecan- or taxane-based regimen, with a recent phase III study of 193 patients demonstrating improved OS (median 5.1 months chemotherapy vs 3.8 months BSC, HR 0.63) (Kang et al, 2012).

The ATTAX2 study has shown that the combination of weekly docetaxel with cetuximab is a feasible treatment combination regimen for docetaxel-refractory advanced oesophagogastric cancer, with manageable rates of grade $3 / 4$ toxicities. The observed response rate, median PFS and OS times are modest, but it is important to bear in mind that the patient population enrolled has a relatively poor prognosis. In this context, the combination of

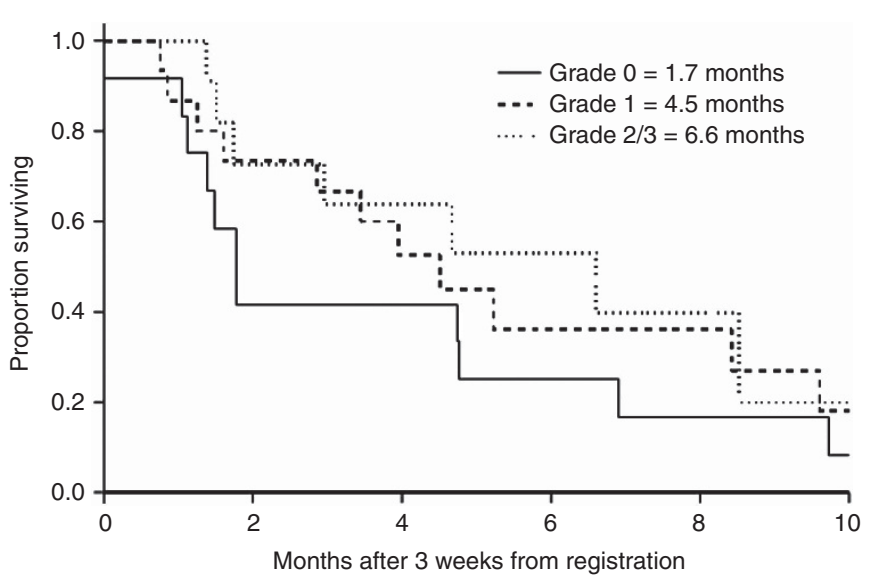

Figure 3. Kaplan-Meier curves of progression-free survival for patients with grade 0 , grade 1 and grade $2 / 3$ acneiform rash $(n=38)$.

docetaxel and cetuximab appeared to demonstrate a level of activity, as there was tumour regression on waterfall plots and the patient population achieved an OS time comparable to other second-line studies. It is notable that responses occurred despite progression soon after docetaxel, suggesting that the activity is related to the EGFR inhibitor either alone or in combination.

The role of EGFR inhibitors in oesophagogastric cancer is however somewhat uncertain, as two recent phase III studies have failed to show any evidence of improved outcomes in the first-line setting (Carter, 2012; Waddell et al, 2012). In addition, a randomised study of gefitinib in the second-line setting of oesophageal cancer showed improved PFS to a modest extent, but did not affect OS (Ferry et al, 2012). Furthermore, a recently published phase II study showed minimal activity for cetuximab monotherapy in second line (RR 3\%, PFS 1.6 months, OS 3.1 months) (Chan et al, 2011).

Many studies using a range of EGFR inhibitors have noted a correlation between better clinical outcomes and the development of rash (Susman, 2004; Bonner et al, 2010; Gatzemeier et al, 2011; Saridaki et al, 2011; Fleming et al, 2012). Although, it did not achieve statistical significance, our data is also in keeping with these observations with a similar trend to superior outcomes using a landmark analysis, suggesting that rash may also be a pharmacodynamic marker of benefit with EGFR inhibitors in oesophagogastric cancer.

We undertook an exploratory analysis of biomarkers as potential predictors of clinical benefit in this study. However, in keeping with other studies (refer to COSMIC), the rate of KRAS, $B R A F$, and PI3KCA mutations in this disease was very low, which precludes any definitive conclusions being drawn.

In conclusion, this study has demonstrated some activity for the combination of cetuximab and docetaxel in docetaxel-refractory oesophagogastric cancer. The degree of benefit is modest, but is in keeping with other studies in the second-line setting in this disease.

\section{ACKNOWLEDGEMENTS}

This study was supported with an unrestricted educational grant by Merck Serono. Drugs were provided by Merck Serono and SanofiAventis. Numerous individuals from many institutions participated to complete this study. We thank everyone involved for their efforts.

NHMRC Clinical Trials Centre, University of Sydney: Michelle M Parry, Kate Wilson, Diana Zannino, Tatiana Sourjina, Sian Hicks, Corona Gainford, Mary-Ellen Harrod.

Principal investigators: Niall C Tebbutt, Austin Health; Andrew H Strickland, Monash Medical Centre; Guy A van Hazel, 
Sir Charles Gairdner Hospital; Nick Pavlakis, Royal North Shore Hospital; Vinod Ganju, Frankston Hospital; Euan Walpole, Princess Alexandra Hospital; Fred Kirsten, Bankstown-Lidcombe Hospital; Craig Underhill, Border Medical Oncology; Timothy J Price, Queen Elizabeth Hospital.

Study Coordinators: Donna Haberl, Austin Health; Linda Blackwell, Monash Medical Centre; Lyn Cox, Sir Charles Gairdner Hospital; Pippa Bannister, Royal North Shore Hospital; Sally Blandford, Frankston Hospital; Paul Baxter, Princess Alexandra Hospital; Mafizul Hoque, Bankstown-Lidcombe Hospital; Jacqui McBurnie, Border Medical Oncology; Greer Dymmott, Queen Elizabeth Hospital.

We thank Hongdo Do for verifying and analysing the highresolution melting results.

Trial registration: The trial was registered with the ANZCTR as trial number ACTRN12606000181505.

\section{REFERENCES}

Bonner JA, Harari PM, Giralt J, Cohen RB, Jones CU, Sur RK, Raben D, Baselga J, Spencer SA, Zhu J, Youssoufian H, Rowinsky EK, Ang KK (2010) Radiotherapy plus cetuximab for locoregionally advanced head and neck cancer: 5-year survival data from a phase 3 randomised trial, and relation between cetuximab-induced rash and survival. Lancet Oncol 11(1): 21-28.

Carter P (2012) Merck: EXPAND Trial of Erbitux in advanced gastric cancer does not meet primary endpoint (Merck KGaA press release, 5 July 2012). Merck KGaA: Darmstadt.

Chan JA, Blaszkowsky LS, Enzinger PC, Ryan DP, Abrams TA, Zhu AX, Temel JS, Schrag D, Bhargava P, Meyerhardt JA, Wolpin BM, Fidias P, Zheng H, Florio S, Regan E, Fuchs CS (2011) A multicenter phase II trial of single-agent cetuximab in advanced esophageal and gastric adenocarcinoma. Ann Oncol 22(6): 1367-1373.

Cunningham D, Humblet Y, Siena S, Khayat D, Bleiberg H, Santoro A, Bets D, Mueser M, Harstrick A, Verslype C, Chau I, Van Cutsem E (2004) Cetuximab monotherapy and cetuximab plus irinotecan in irinotecanrefractory metastatic colorectal cancer. N Engl J Med 351(4): 337-345.

Do H, Dobrovic A (2012) Dramatic reduction of sequence artefacts from DNA isolated from formalin-fixed cancer biopsies by treatment with uracil- DNA glycosylase. Oncotarget 3(5): 546-558.

Ferry DR, Dutton S, Mansoor W, Thompson J, Harrison M, Abbas H, DahleSmith A, Chatterjee A, Falk S, Garcia-Alonso A, Fyfe DW, Hubner R, Gamble T, Peachey L, Davoudianfar M, Pearson SR, Julier P, Jankowski J, Midgely R, Petty RD (2012) Phase III multi-centre, randomised, doubleblind, placebo-controlled trial of gefitinib versus placebo in esophageal cancer progressing after chemotherapy, COG (Cancer Oesophagus Gefitinib). Ann Oncol 23(suppl9): ixe12.

Fleming MT, Sonpavde G, Kolodziej M, Awasthi S, Hutson TE, Martincic D, Rastogi A, Rousey SR, Weinstein RE, Galsky MD, Berry WR, Wang Y, Boehm KA, Asmar L, Rauch MA, Beer TM (2012) Association of rash with outcomes in a randomized phase II trial evaluating cetuximab in combination with mitoxantrone plus prednisone after docetaxel for metastatic castration-resistant prostate cancer. Clin Genitourin Cancer 10(1): 6-14.

Gatzemeier U, von Pawel J, Vynnychenko I, Zatloukal P, de Marinis F, Eberhardt WE, Paz-Ares L, Schumacher KM, Goddemeier T, O’Byrne KJ, Pirker R (2011) First-cycle rash and survival in patients with advanced non-small-cell lung cancer receiving cetuximab in combination with firstline chemotherapy: a subgroup analysis of data from the FLEX phase 3 study. Lancet Oncol 12(1): 30-37.

Kang JH, Lee SI, Lim do H, Park KW, Oh SY, Kwon HC, Hwang IG, Lee SC, Nam E, Shin DB, Lee J, Park JO, Park YS, Lim HY, Kang WK, Park SH (2012) Salvage chemotherapy for pretreated gastric cancer: a randomized phase III trial comparing chemotherapy plus best supportive care with best supportive care alone. J Clin Oncol 30(13): 1513-1518.

Kim ES, Mauer AM, William Jr. WN, Tran HT, Liu D, Lee JJ, Windt P, Hong WK, Vokes EE, Herbst RS (2009) A phase 2 study of cetuximab in combination with docetaxel in chemotherapy-refractory/resistant patients with advanced nonsmall cell lung cancer. Cancer 115(8): 1713-1722.

Krypuy M, Newnham GM, Thomas DM, Conron M, Dobrovic A (2006) High resolution melting analysis for the rapid and sensitive detection of mutations in clinical samples: KRAS codon 12 and 13 mutations in non-small cell lung cancer. BMC Cancer 6: 295.

Saridaki Z, Tzardi M, Papadaki C, Sfakianaki M, Pega F, Kalikaki A, Tsakalaki E, Trypaki M, Messaritakis I, Stathopoulos E, Mavroudis D, Georgoulias V, Souglakos J (2011) Impact of KRAS, BRAF, PIK3CA mutations, PTEN, AREG, EREG expression and skin rash in $>/=2$ line cetuximab-based therapy of colorectal cancer patients. PLoS One 6(1): e15980.

Slamon DJ, Leyland-Jones B, Shak S, Fuchs H, Paton V, Bajamonde A, Fleming T, Eiermann W, Wolter J, Pegram M, Baselga J, Norton L (2001) Use of chemotherapy plus a monoclonal antibody against HER2 for metastatic breast cancer that overexpresses HER2. N Engl J Med 344(11): 783-792.

Susman E (2004) Rash correlates with tumour response after cetuximab. Lancet Oncol 5(11): 647.

Tebbutt NC, Cummins MM, Sourjina T, Strickland A, Van Hazel G, Ganju V, Gibbs D, Stockler M, Gebski V, Zalcberg J (2010) Randomised, noncomparative phase II study of weekly docetaxel with cisplatin and 5-fluorouracil or with capecitabine in oesophagogastric cancer: the AGITG ATTAX trial. Br J Cancer 102(3): 475-481.

Waddell TS, Chau I, Barbachano Y, Gonzalez de Castro D, Wotherspoon A, Saffery C, Middleton GW, Wadsley J, Ferry DR, Mansoor W, Lewis Crosby TD, Coxon FY, Smith D, Waters JS, Iveson T, Falk T, Slater S, Okines AFC, Cunningham D (2012) A randomized multicenter trial of epirubicin, oxaliplatin, and capecitabine (EOC) plus panitumumab in advanced esophagogastric cancer (REAL3). J Clin Oncol 30: (abstract LBA4000).

This work is published under the standard license to publish agreement. After 12 months the work will become freely available and the license terms will switch to a Creative Commons AttributionNonCommercial-Share Alike 3.0 Unported License.

Supplementary Information accompanies the paper on British Journal of Cancer website (http://www.nature.com/bjc) 